NBSIR 78-1520

\title{
Ultrasonic Transducer Power Output By Modulated Radiation Pressure (with details)
}

M. Greenspan, F.R. Breckenridge, and C.E. Tschiegg

Ultrasonic Standards Section Mechanical Processes Division National Engineering Laboratory National Bureau of Standards

Washington, D.C. 20234

July 1978

Final

Issued September 1978

\section{Report to}

Department of the Navy Office of Naval Research 2 Arlington, Virginia 22217

Government Order N00014-78-F-0007 


\section{ULTRASONIC TRANSDUCER POWER OUTPUT BY MODULATED RADIATION PRESSURE (WITH DETAILS)}

M. Greenspan, F.R. Breckenridge, and C.E. Tschiegg

Ultrasonic Standards Section Mechanical Processes Division National Engineering Laboratory National Bureau of Standards

Washington, D.C. 20234

July 1978

Final

Issued September 1978

Report to

Department of the Navy

Office of Naval Research

Arlington, Virginia 22217

Government Order N00014-78-F-0007

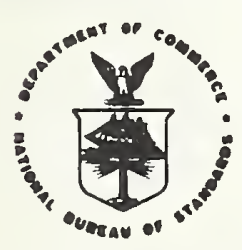

U.S. DEPARTMENT OF COMMERCE, Juanita M. Krops, Secrotery Dr. Sidney Harman, Under Secrotery Jordan J. Baruch, Assistant Secrotery for Science and Tochnology NATIONAL BUREAU OF STANDARDS. Ernest Ambler, Diroctor 

ULTRASONIC TRANSDUCER POWER OUTPUT BY

MODULATED RADIATION PRESSURE (WITH DETAILS)

M. Greenspan ${ }^{\text {l. }}$, F. R. Breckenridge and C. E. Tschiegg

National Engineering Laboratory

National Bureau of Standards

Washington, D.C. 20234

\section{ABSTRACT}

We have set up and are using an apparatus for the measurement of total sound power output of a piezoelectric transducer radiating into water. This apparatus combines the better features of previously used methods which depend on radiation pressure. The input is modulated at a low frequency and the output power is intercepted by a target which experiences a force at the modulation frequency. The target is mounted on the armature of an electromagnetic receiver provided with an independent coil through which a current at the modulation frequency is adjusted in amplitude and phase, either manually or automatically by feedback, to arrest the motion of the armature. When the armature is stationary the force depends only on the current, and the apparatus can be calibrated using direct current and dead weights. It is thus absolute. In practice, the carrier frequency is swept over any part of the range 0.1 to $15 \mathrm{MHz}$ while a recording of power output versus frequency is made. The results of comparisons made with those of other methods are encouraging. Examples of curves from normal and defective transducers are shown. Key words: calibration of transducers; medical ultrasonics; modulated radiation pressure; radiation pressure; transducers; non-destructive evaluation; ultrasonic transducers 
1. INTRODUCTION

2. METHOD AND THEORY

3. APPARATUS

3.1 General

3.2 Signal source

3.3 Tank and target

3.4 Receiver and balancing system

3.5 Receiving electronics

3.6 En i ionmental considerations

3.7 Error analysis

4. SOME RESULTS

4.1 Linearity and comparison with other methods

4.2 Sample frequency-response graphs

5. CONCLUSIONS

6. REFERENCES

APPENDIX A. LEVELING CONTROL APPENDIX B. DIODE SLIDEBACK VOLTMETER APPENDIX C. MEASUREMENT AND MONITORING OF BL-PRODUCT APPENDIX D. PHASE SHIFTER 
M. Greenspan ${ }^{1}$, F. R. Breckenridge and C. E. Tschiegg

\section{National Engineering Laboratory National Bureau of Standards Washington, D.C. 20234}

\section{INTRODUCTION}

We have set up and are using an apparatus for the measurement of the total sound power output of a piezoelectric transducer radiating into water. The data are presented as a graph of radiation conductance (watts radiated per input volts - squared) versus frequency, over a range which includes one or more of the low-order resonances of the transducer.

The transducers used for non-destructive evaluation (NDE) are subject to hard wear and abuse, and as a result may develop various defects, such as complete or partial detachment of the wearplate or of the backload, cracks in either of these or in the active material, partial depolarization and the like. Consideration of the equivalent circuit of a transducer suggests that the $\mathrm{P}$ vs $\mathrm{F}$-curve can be used to monitor the condition of a transducer; there might be an application to quality control during manufacture as we11. The frequency of maximum power output and the bandwidth relative to that frequency are easily and quickly obtained with this apparatus. These considerations led us to undertake the work but some of them apply equally well to medical transducers. Especially obvious is the application to continuous-wave dosimetry. 
Radiation pressure was chosen as the basis for the measurement. Recent reviews of this subject by Rooney and Nyborg[1] ${ }^{2}$ and by Zieniuk and Chivers [2] provide extensive references. Radiation pressure is a steady pressure which, under the conditions at which it is measured, depends on the difference in the energy densities on the two sides of the target. For a perfectly absorbing target in a collimated beam, the total radiation force equals the incident power divided by the speed of sound in the medium. The same is true for a beam incident at 45 deg on a specular target of any reflection coefficient. For propágation in water, this force is roughly $67 \mathrm{mg}$-weight per watt; it is commonly measured by weighing with an analytical balance or with a modified hydrometer.

We have chosen to use modulated radiation pressure. In this case the input voltage to the transducer is amplitude-modulated at a low frequency; the force on the detector now has a component at the modulating frequency, and the detector is in effect a low-frequency receiver. In this way the various secular drifts which plague dc measurements are avoided and advantage can be taken of narrow-band ac signal-processing techniques at the fixed modulation frequency while the carrier frequency is independently varied over a wide range. This method was adumbrated in 1928 by Sivian [3], who used a Rayleigh disk as a detector. It was further developed in 1950 and 1951 by Barone and Nuovo [4] who used

$\overline{2}$ Numbers in square brackets refer to literature citations in Section 6. 
an ordinary telephone receiver. In 1953 McNamara and Beyer [5] and in 1956, Mokhtar and Youssef [6] successfully measured the sound absorption of several liquids each, using capacitive detectors, and in 1960, Hanel [7] developed a small thermoelectric microphone which proved, as expected, to be much more stable when used with modulated than unmodulated, radiation.

In each of the above cases the measurements were relative, rather than absolute, as in ours, although Mokbtar and Youssef could perhaps have modified their apparatus had they wished, and Barone and Nuovo calibrated their apparatus by making duplicate measurements of the dc component of the radiation pressure by means of a hydrometer.

The input voltage has the form

$$
E=E_{0}(1+m \sin p t) \sin \omega t,
$$

in which $\omega$ and $p$ are the carrier and modulation pulsatances, and $m$ is the modulation index, so that the voltages at the crest and trough of the upper envelope are given by

$$
E_{1}=(1+m) E_{0} \text { and } E_{2}=(1-m) E_{0} \text {, }
$$

respectively. We define a transducer radiation conductance, $G_{\Upsilon}$, as the 
sound power output, P, divided by the square of the input voltage, E, so that

$$
P=E^{2} G_{r}=E_{0}^{2} G_{r}(1+m \sin p t)^{2} \sin ^{2} u t .
$$

If the power $P$ in Eq. 3 is measured using a device having a properly chosen time constant, it will appear to have a component, $P_{P^{\prime}}$, (among others) which varies at the modulation frequency, $p / 2 \pi$; its amplitude is, from Egs. (3) and (2)

$$
\left|P_{p}\right|=m E_{o}^{2} G_{r}=\left(E_{1}^{2}-E_{2}^{2}\right) G_{r} / 4 \text {. }
$$

On the other hand, this power amplitude can also be expressed in terms of the amplitude of the radiation force, $F_{p}$, at the frequency $p / 2 \pi$; in the case of a perfectly absorbing target, or if the beam is incident at $45 \mathrm{deg}$ on any target we have

$$
\left|P_{p}\right|=\left|F_{p}\right| c,
$$

in which $c$ is the speed of sound in the mediun. Finally, from Eqs. (4) and (5)

$$
G_{r}=\frac{4\left|F_{p}\right| c}{E_{1}{ }^{2}-E_{2}^{2}}
$$


Thus the measurement of the radiation conductance, $G_{r}$, of a transducer reduces to that of a radiation force and of two voltages. It is important to note that only the crest voltage, $E_{l}$, need be measured accurately. If $E_{2}$ is about 10 percent of $E_{1}$ (corresponding to a modulation index of $m=.82$ ), a 10 percent error in $E_{2}$ produces an error in the final result of only 0.2 percent. In fact if m exceeds 0.82 , $E_{2}$ may be taken as zero with an error less than 1 percent. 


\section{APPARATUS}

\subsection{General}

A schematic of the apparatus is shown in Fig. 1. The sound beam is intercepted by a reflecting target which deflects it through $90^{\circ}$. This target is rigidly connected to the armature of an electromagnetic receiver, the output of which is processed and eventually plotted $v$ s the carrier frequency as it is swept over the range of interest. Only that component of the output at the modulation frequency is used. Mounted on the same armature is an independent coil operating in a separate magnetic field. A current at the modulation frequency is passed through this coil and adjusted in amplitude and in phase to arrest the motion of the armature. Under this condition the force depends on the current only, so that the calibration can be effected usil.g direct current and dead weights. It is our practice to perform the balance manually at one frequency, usually the lowest resonance frequency of the transducer under test, for each run. Sometimeș we employ automatic balancing, by means of feedback, continuously throughout the run, in which case the feedback current serves as the recorded output. The manual method gives a better signal-to-noise ratio... Mokhtar and Youssef [6] also made use of a balancing technique, but not for absolute measurement. They had not only to arrest the motion at the modulating frequency, but also to neutralize the steady deflection, produced by the steady component of the radiation pressure, of the moving plate of the capacative detector. 


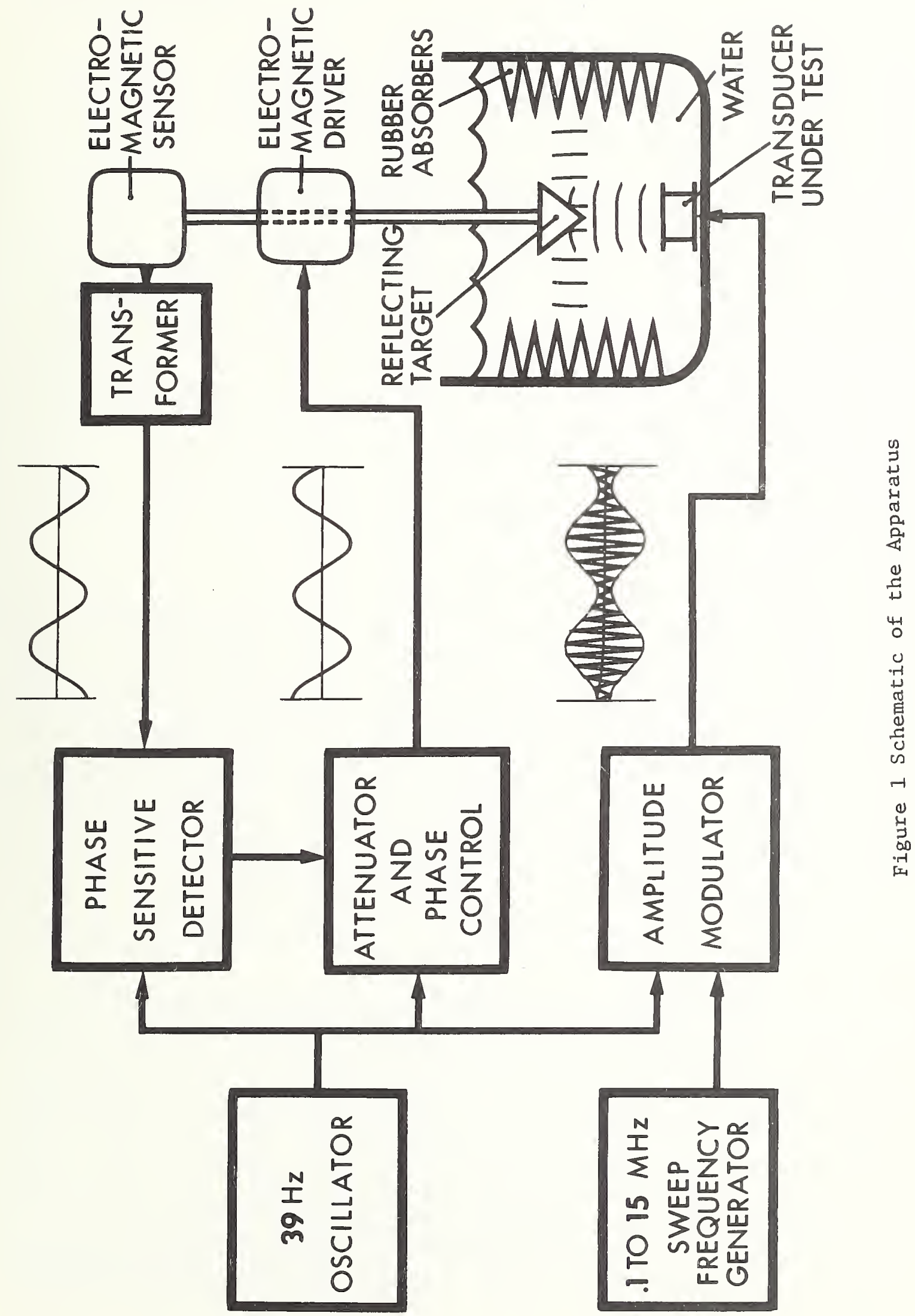



The signal originates in a frequency synthesizer ${ }^{3}$ (PRD Electronics, Inc. Model 7808$)^{4}$ of range $50 \mathrm{kHz}$ to $80 \mathrm{MHz}$ which can deliver up to $10 \mathrm{~V}$ into 50 onms. The frequency can be swept either manually or automatically over a band up to $10 \mathrm{MHz}$ wide; the rate may be as low as $100 \mathrm{sec}$ per sweep during automatic operation. Amplitude modulation is provided from an external RC Wien-bridge oscillator at about $39 \mathrm{~Hz}$; the modulation index is kept at about 0.85 ; above this value some envelope distortion sets in. The output is fed, via a 50-ohm coaxial cable, to a commercial broadband (0.25-110 MHz) RF power amplifier having a gain of $50 \mathrm{~dB}$ and

${ }^{3}$ It is not necessary that the signal source be a frequency synthesizer. In addition to the desired frequency range, the instrument should have the following features; automatic and manual frequency sweep, voltage-controlled output amplitude which can follow the modulation frequency with low envelope distortion up to at least 80-percent modulation index, good voltage leveling at the output. jack against changes in both frequency and load impedence, and separate dc output proportional to frequency. These requirements can perhaps be met at lower cost by a waveform generator.

${ }^{4}$ Certain commercial equipment, instruments and materials are identified in this report as examples of components which have been found to be satisfactory for the present purpose. Others with similar specifications and operating characteristics vill in most cases do equally well. In no case does such identification imply recommendation or endorsement by the National Bureau of Standards, nor does it imply that the material or equipment identified is necessarily the best. available for the purpose. 
which can deliver $20 \mathrm{~W}$ into 50 ohms. Another 50-ohm coaxial cable connects the output to the transducer under test, a step-down transformer 5 being interposed when required. It is necessary that, during any one sweep, the voltage on the transducer remain constant; this is accomplisbed by means of an AVC circuit which feeds to the voltage-control input of the signal generator a signal derived from the peak value of the voltage on the transducer, as detected by a diode-capacitor combination. Added tio the control signal is one from the modulation oscillator, so that the modulation index and peak amplitude are held constant during the sweep. 6

For measurement at a single frequency, whicb is sometimes all that is required, the AVC circuit may be dispensed with. Also, under some extreme conditions, the AVC-circuit does not have adequate range, and the data have to be taken point by point. For instance, at voltages below about 2 or 3 volts, such as might sometimes be used with highfrequency ceramic transducers, the AVC circuit produces an unacceptable distortion of the modulation envelope.'Again, some low-frequency, heavily damped quartz transducers have so high a radiation impedance that tuning at the transducer input is required to produce a workable output; the tuning must be adjusted manually at each frequency. A' simple L-network, consisting of a fixed series inductor and variable shunt capacitor, is satisfactory in most cases. A greater frequency range can be obtained with a tapped inductor.

${ }^{5}$ A 4 to 1 (50 to 3 ohms) step-down transformer supplied by Electric Navigation Industries.

${ }^{6}$ See Appendix A 
As we have already pointed out, the peak voltage, $E_{1}$, on the transducer needs to be measured accurately, while the trough voltage, $E_{2}$, or the ratio, $E_{2} / E_{1}$, is not at all critical (for high modulation index). Thus it is more than sufficient to get $E_{2} / E_{1}$ from readings on an oscilloscope screen. For measurement of $E_{1}$ we have constructed a diode slideback voltmeter ${ }^{7}$. We have modified the circuit shown by Terman [8] in several ways. Instead of a vacuum diode we use a silicon diode (or two in series) having an abrupt break. Our circuit has the form of a bridge, so that by means of a small variable capacitor in one arm, the effects of the diode capacitance can be minimized. Furthermore, we detect not the current, but the voltage unbalance of the bridge. The detector is an oscilloscope having a balanced input. Finally, the dc slideback voltage is measured with a digital voltmeter.

\section{3 Tank and target}

The water into which the sound is radiated is contained in a cylindrical gláss dish (a crystallizing dish) $19 \mathrm{~cm}$ in diameter by 10 cm high. See Fig. 1 and 2. In the center of the bottom of the dish is

a hole large enough to admit the largest transducer to be tested. 8 The transducer is pushed through a close-fitting hole in a piece of foamed

${ }^{7}$ See Appendix $B$.

8 The hole in the bottom of the glass dish was cut in a drill press using a brass "cookie cutter" and silicon-carbide grit. 
polystyrene which in turn is cemented reversibly to the outside. 9 It radiates vertically upwards and the sound beam is intercepted by a target.

The target, machined from stainless steel, has the shape of a cone of half-angle $45 \mathrm{deg}$. It is hollow and air-filled, with walls about $0.6 \mathrm{~mm}$ thick, and has a maximum diameter of $36 \mathrm{~mm}$. As the sound is incident at $45 \mathrm{deg}$ and reflected in directions at right angles to the axis of the incident wave, the radiation force is independent of the reflection coefficient. There is a disadvantage to having, as we do, a reflection coefficient of nearly unity; it is that the sound, reflected in a radial fan to the walls of the dish, must be there almost completely absorbed, else the returning energy, upon reflection from the target, will exert upon it an unknown force. Therefore the side of the dish was lined with a set of wedges, visible in the photograph, Fig. 2 , which were cut from soft rubber pencil erasers and cemented in place with silicone-rubber adhesive. Measurements on the rubber material showed the normal amplitude reflection coefficients to be always much less than 0.2 (energy reflection $<0.04$ ) for frequencies greater than $1 \mathrm{MHz}$, and the transmitted sound to be almost completely absorbed over

9 The foamed polystyrene referred to is the material sold in sheets of various thicknesses as thermal insulation. The hole must be accurately sized to provide a push fit for the transducer, free of leaks. Very good holes can be made in a lathe using an accurately dressed cork borer or similar coring tool held in a chück on the slowly rotating headstock, while the work is held flat against a pad in the tailstock, backed up by a sheet of the same material. This "seal," which is cemented to the outside of the bottom of the tank with beeswax and rosin [16], can be removed using a hot-air gun and reused several times. 


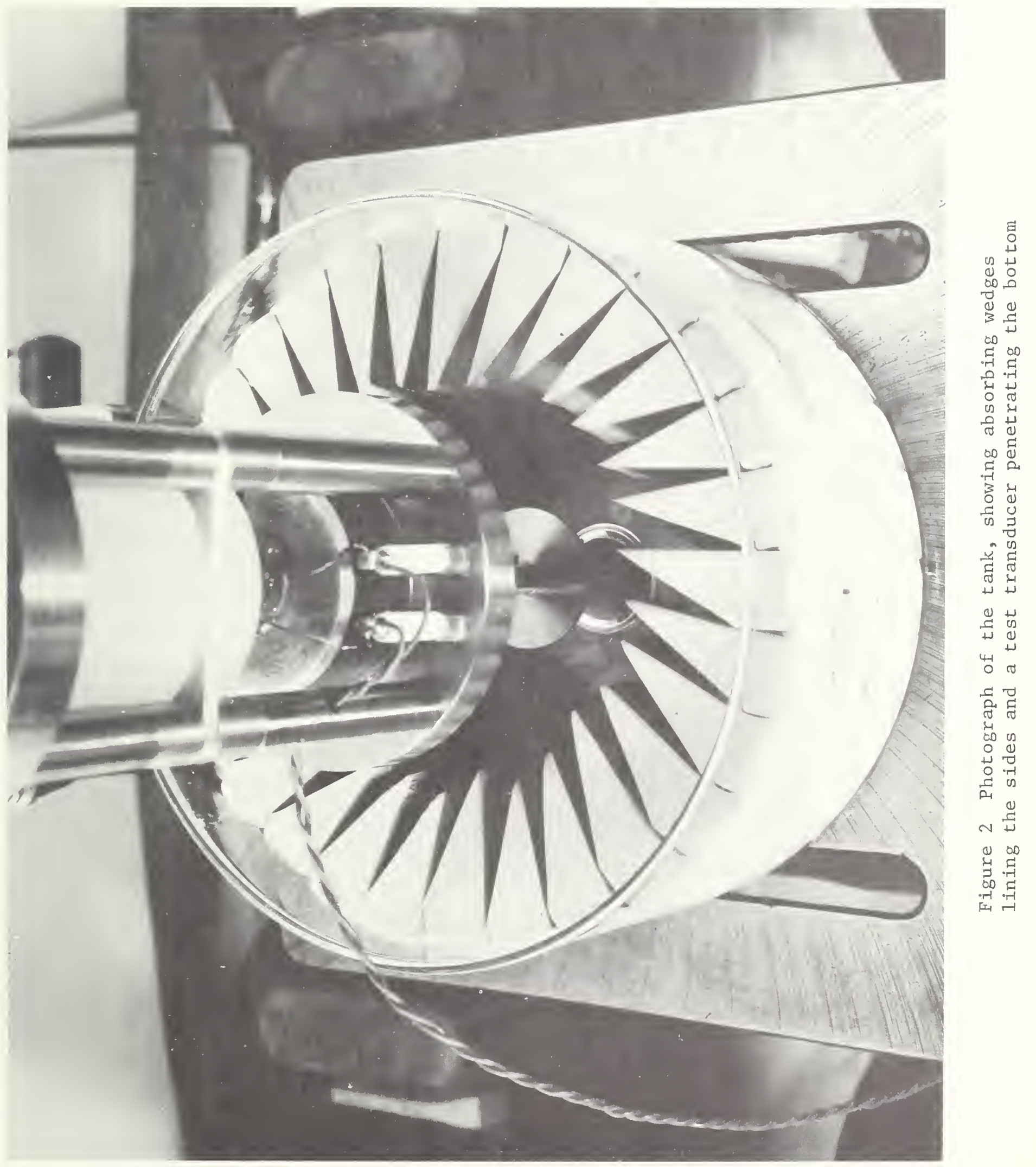


a travel of 3 or $4 \mathrm{~cm}$; hence the wedge structure, providing as it does for multiple reflections, might be expected to act as a nearly ideal absorber. Pulse echo measurements show this to be the case.

The absorbing wedges are made from soft-rubber erasers sold under trade names such as RubkZeen. Each eraser, about 5 by 2.5 by $1.8 \mathrm{~cm}$, was divided by means of a single, angled cut to yield two wedges as shown in Fig. 3. Use of a simple jig facilitates the operation.

We have, also, a tank lined with the same erasers, not cut into wedges, but cemented in so that the sound is incident on the broad faces. This tank shows a small but noticeable return when examined by the pulse-echo method. It is perhaps good enough, but the additional labor in making a wedge-lined tank, which shows no discernible return, is slight, and we thought it worth wiille to make one. There is some evidence that the rubber hardens with age, especially under water, and it may become necessary to replace it after a few years.

If the target were made of a partially sound-absorbing material, such as soft rubber, the requirements for absorption at the lateral walls of the tank would be easier to meet. Because it is difficult to produce and to maintain a sharp point with such material, and because it would have to be rather thick, in the axial direction, so that sound would not enter the water from the back, we preferred the steel. However, the idea might be worth a try.

During the course of the work it was observed that, in some cases, the target reflects some sound (up to about 5 percent amplitude reflection) 
back to the transducer. This occurs at a frequency of about $1.2 \mathrm{MIHz}$ (noticeable from about 0.9 to $1.5 \mathrm{MHz}$ ) but only if the transducer has a diameter at least almost as large as the maximum diameter of the target. We think this is a "coincidence" effect which occurs when the trace speed (on the target) of the wave in the water is nearly equal to the flexural-wave speed in the wall of the target. Although none of the results given here are affected we are designing another target which we hope will be better behaved.

\subsection{Receiver and Balancing System}

The receiver is a model 108 dynamic vibrator (shaker) made by Ling Electronics: It is shown at $A$ in Fig. 4. The frame was extended with 4 posts, $B$, to accomodate the shelf, $C$, which supports the balancing magnet, D. An extension to the armature, which is a stainless steel tube, E, (O.D. $63 \mathrm{~mm}$, wall thickness $1.0 \mathrm{~mm}$ ) supports the balancing moving coil, F, near one end and the target, $G$, at the other. It is: constrained against lateral motion by three flexure wires, $H$, (0.4 $\mathrm{m}$ music wire) tensioned by three No. 2 cup-point set screws, I, into which they are silver soldered, and three tensioning nuts, J. The screws pass through clear holes, and are held stationary with a wrench while the nuts are adjusted. The tensioning screws and nuts allow the poving coil to be centered in its gap and the resonance frequency of the moving system to be adjusted. 
<smiles>C1CC2CCCC3CC(C1)C23</smiles> 
Figure 4

Receiving and Balancing Assembly
A. Ling Model 108 Vibrator, Schematic
a. voice coil
b. magnet
B. Posts
C. Shelf
D. Balancing Magnet
E. Armature Extension
F. Balancing Voice Coil
G. Target
H. Flexure Wires
I. Tensioning Screws
J Tensioning Nuts 


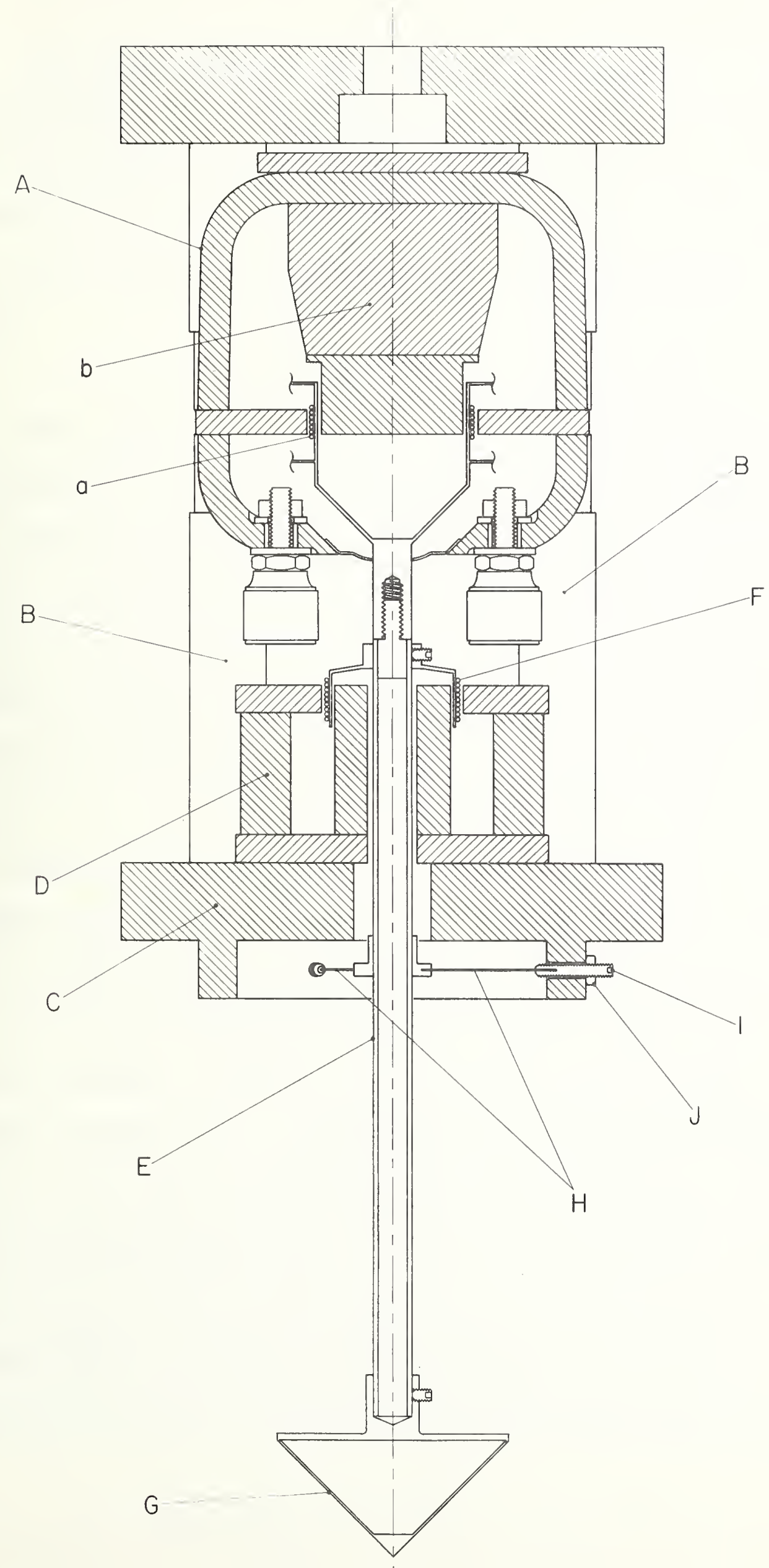



The entire vibrating assembly is so stiff that the moving coil of the vibrator, A, follows the motion of the target and therefore generates an emf (in this case through about 30 ohms) which is proportional to the velocity of the target. With the target in water, the assembly is resonant at the modulation frequency of about $39 \mathrm{~Hz}$, with a $Q$ of about 7.6 .

The balancing magnet, $D$ and balancing coil, $F$, which are the basic components of the calibration system, were scavenged from a loudspeaker of dubious antecedents. As already explained, the current at the modulating frequency (here $39 \mathrm{~Hz}$ ) is passed through the coil and adjusted in amplitude and in phase to arrest the motion, owing to the radiation pressure, of the target, that is, to bring the emf generated in the microphone coil to zero. Under the condition of zero velocity, the force, $F$, is related to the current, $I$, by $F=B L I$, independent of frequency. The BL-product can thus be measured at dc. 10 There is always some worry that the field of the balancing magnet will drift or even change suddenly. Re-determination of the BL product is tedious; we therefore monitor it by measuring the charge, released by the balancing coil, produced by addition to or abstraction from the target of a fixed weight, usualiy $20 \mathrm{~g}$. A simple charge amplifier, based on an integratedcircuit operational amplifier, serves this purpose well, and the entire operation, including setup, takes only an hour or so. 10

${ }^{10}$ See Appendix C. 
The microphone and balancing assembly is mounted on the arbor of a cannibalized, bench-model drill press, making it easy to raise or lower the target relative to the dish, which sits on the table of the drill press. Figure 5 is a photograph of the assembly.

\subsection{Receiving electronics}

See Fig. 1. The output of the receiver is fed to a phase-sensitive detector (lock-in amplifier) ${ }^{11}$, the reference voltage for which is derived from the $39-\mathrm{Hz}$ modulating oscillator. A transformer ${ }^{12}$, having a voltage gain in situ of 246 is interposed; no preamplifier is necessary. The dc output of the lock-in amplifier actuates the $y$-axis of an $x, y$ recorder; the $\mathrm{x}$-axis is actuated by a dc voltage, proportional to frequency, which is available from the signal generator.

Calibrating current for the balancing coil is derived from the modulating oscillator. via an attenuator (200 ohms) and phase shifter ${ }^{13}$; the input voltage at the attenuator is read on a digital voltmeter.

11 At least one model that we have tried is made unstable by rf fields in its vicinity, particularly at frequencies above about $10 \mathrm{MHz}$. Therefore, before buying a lock-in amplifier especially for the present purpose, it should be tried out.

${ }^{12}$ Such transformers are used in geophysical instruments. Ours is very old; the company that made it is no longer in business. 


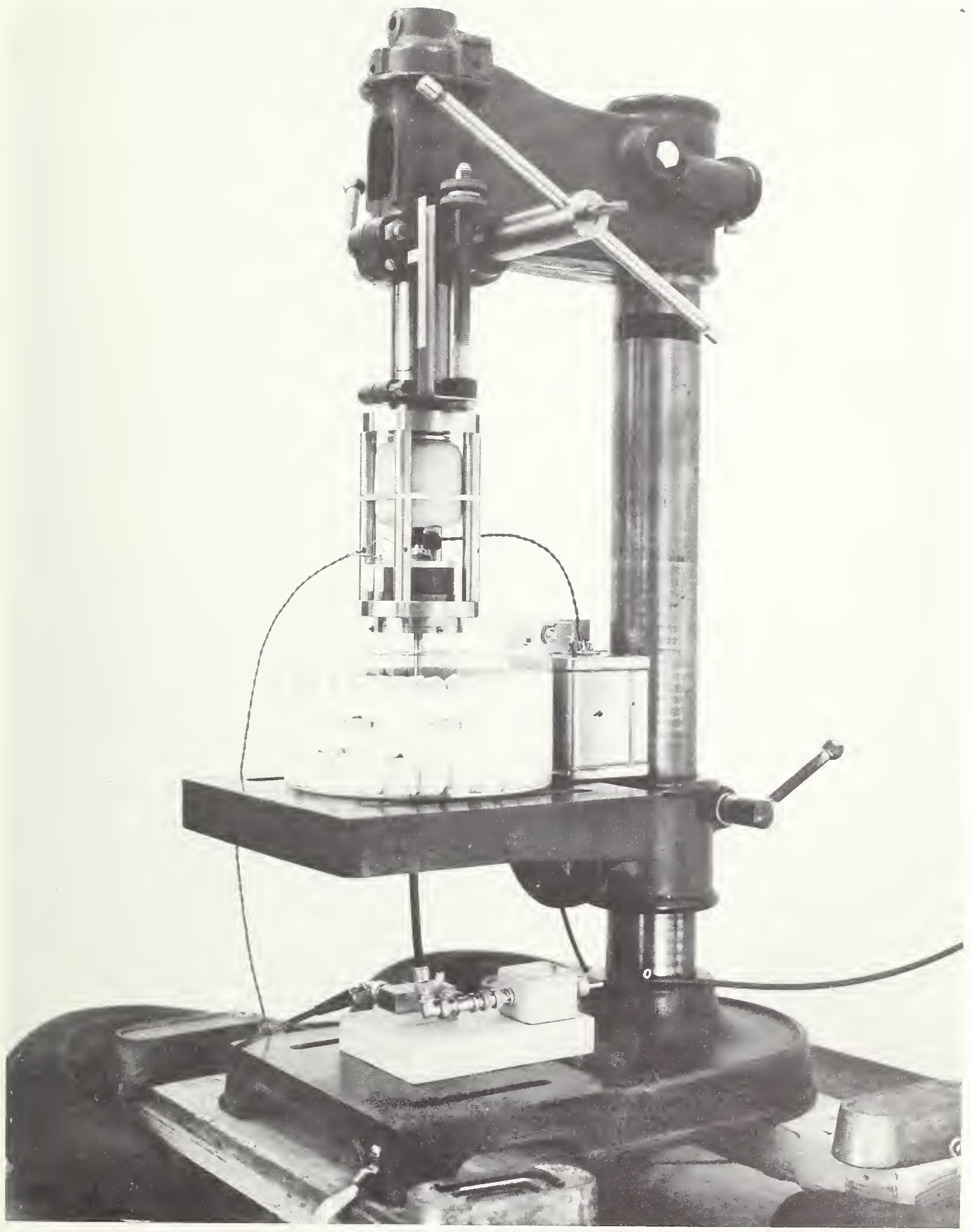

Figure 5 Photograph of the Assembly showing how the several parts are mounted on a drill press 

The 200-ohm attenuator is loaded by the balancing coil, which has a resistance of about 5 ohms, in series with a pad (about 195 ohms) giving a total measured load of 200.0 ohms. The small inductive reactanceof the coil is thus swamped by the resistance of the pad. The attenuator itself is accurate to only about one percent and therefore it was calibrated in situ, for each combination of settings in use, by means of a digital voltmeter accurate to about 0.01 percent.

For automatic operation, during which the output of the lock-in amplifier is held near zero by feedback, the y-axis of the recorder is actuated by the voltage on the input side of the balancing-current attenuator. 14

\subsection{Environmental considerations}

The signal-to-noise ratio and the ultimate sensitivity of our apparatus are limited not by the intrinsic, thermal noise, but by airand structure-borne sound. From this point of view the drill press, al though it is a very convenient mount, would seem to be a poor choice. It was found that the drill press has numerous resonances in the range 15 to $90 \mathrm{~Hz}$; in the $40-\mathrm{Hz}, 1 / 3$ octave band it was much quieter than at any other in the range and therefore the operating (modulation) frequency was chosen in this band. It would seem then, that what we pay for the

14 We make little use of this feature because of the relatively poor signal-to-noise ratio:. For those who wish to try it, a simple way to get a feedback signal (at the modulation frequency) proportional to the output is to multiply a signal from the modulation oscillator by the dc output of the lock-in amplifier. An integrated-circuit analog multiplier is convenient for this purpose. 
convenience is a lack of flexibility in the choice of the operating frequency.

The drill press sits on four partially inflated inner tubes, each $25 \mathrm{~cm}$ O.D. by $10 \mathrm{~cm}$ I.D., which in turn rest on a laboratory bench. It happens that the laboratory has a floating floor and this helps some. This laboratory is unusually quiet; the SPL in the 40-Hz, 1/3 octave band is about $35 \mathrm{~dB}$ with the air circulation cut off. 15 Provision to by-pass the air was made during the construction of the laboratory and our practice is to cut the air off immediately before each run and to restore the flow immediately after. No fan-cooled equipment is operated during a run except for the power amplifier which is outside the laboratory.

Attention must be paid to dressing the cables for minimum crosstalk at the carrier frequency. Our laboratory is electrically shielded, and the cables to and from the power amplifier run outside the walls.

The minimum power which can be unambiguously detected using a long time constant $(100-200 \mathrm{sec})$ is about $10 \mu \mathrm{W}$; the corresponding radiation force is about $0.7 \mu \mathrm{g}$.wt. Thus a $1 \mathrm{~mW}$ output can be measured at a

${ }^{15}$ As a substitute for the quiet room a good audiometric test booth would probably be adequate. A booth large enough to accomodate all of the equipment and one or two observers would be the most convenient. A much cheaper option is a small booth containing only the noisesensitive parts; the equipment could be operated from without. 
discrete frequency with a signal-to-noise ratio of $40 \mathrm{~dB}$. During a frequency scan, which takes $100 \mathrm{sec}$, the time constant of the lock-in amplifier must be short enough to maintain quasi-equilibrium; we usually use about $0.4 \mathrm{sec}$. An acceptable curve can be obtained if the power at resonance is $10 \mathrm{~mW}$ or more.

\section{G. Error analysis}

We rewrite the basic equation, Eq. (6) as

$$
G_{r}=\frac{4\left|F_{P}\right| c}{E_{1}{ }^{2}\left(1-E_{2}{ }^{2} / E_{1}{ }^{2}\right)}
$$

in order to estimate the error contributed by each term. It is our practice to set a value of $E_{2} / E_{1}$ of about 0.08 ; if this value can be read from the oscillogram within 5 percent, which seems reasonable, this measurement will contribute an error less than \pm 0.07 percent to $\mathrm{G}_{\mathrm{r}} \cdot$

The balanced diode slideback voltmeter used for the measurement of $\mathrm{E}_{1}$ was calibrated against a set of thermal voltage converters 16 constructed by Hermach and Williams [9] at the National Bureau of Standards. Our voltmeter differed from this standard by less than 0.2 percent uf to $15 \mathrm{MHz}$ and by less than 0.4 percent up to $30 \mathrm{MHz}$, except

${ }^{16}$ Similar converters, covering the range $5 \mathrm{~Hz}$ to $50 \mathrm{MHz}$, are available commercially. The standard voltage ranges are $0.5,1,2,3,5,10$, 20,30 and $50 \mathrm{v}$, and each can be used from half to full range. Rated accuracies are $\pm 0.05 \%$ below $1 \mathrm{MHz}$, t0. $1 \%$ below $10 \mathrm{MHz}, \pm 0.2 \%$ below $30 \mathrm{MHz}$ and $\pm 0.5 \%$ below $50 \mathrm{MHz}$. 
for a few outliers. Thus the corresponding error in $G_{\mathbf{r}}$ is less than \pm 0.4 and \pm 0.8 percent up to 15 and $30 \mathrm{MHz}$, respectively.

Errors in the magnitude of the radiation force, $\left|F_{p}\right|$ in Eq. (7) arise in several ways. This force is computed from the BL-product and the magnitude of the current required to arrest the motion of the armature. The random variation in settings of the null are taken as \pm 0.3 percent, for reasons discussed in Section 3.1. Compared with this, the error in the current itself, which is measured using a digital voltmeter, an attenuator, and a known resistor, all accurately calibrated, is considered negligible. The BL-product is known to about \pm 1 percent, as judged from the sensitivity and repeatablilty of its measurement and by observations on its long-time drift. Thus the total error in $F_{p}$ is about \pm 1.3 percent.

No appreciable error owing to the remaining quantity in Eq. (7), c, will arise from the use of handbook values if the temperature of the water is measured to within $0.2^{\circ} \mathrm{C}$.

Another set of errors is contributed by the shape and disposition of the target. For a conical target of half-angle $\phi$, the radiation force, $F$, of a sound beam parallel to the axis of the cone is

$$
F=F_{a}\left(1-R^{2} \cos 2 \phi\right)
$$

in which $F_{a}$ is the force on a perfect absorber, and $R$ is the amplitude reflection coefficient. 
If $\phi=45 \mathrm{deg}$, as is nominally the case in the present apparatus, then $F=F_{a}$ for any value of $R$. This useful result seems to have been first noted by Borgnis. [10] We estimate a possible machining error of $\pm 0.1 \mathrm{deg}$ in $\phi$; then if $\mathrm{R}$ in $\mathrm{Eq}$. (8) be taken as unity, which is about right and is anyway the worst case, the error in the final result is \pm 0.35 percent. But even if $\phi$ were exactly 45 deg, questions of possible misalignment arise. In the ideal case, the axes of the armature, of the cone and of the sound beam are parallel and collinear. Small departures from collinearity are of no monent so long as the target intercepts the entire beam. Suppose, first that the axis of the sound beam is parallel to that of the armature, but that the axis of the reflector is not, owing to an inaccuracy of assembly, Then the force owing to the incident wave is the same as in the ideal case, and the forces owing to the reflected waves, having oppositely directed vertical components on opposite sides of the target, cancel. However, if the axis of the sound beam is inclined at an angle, $\theta$, to that of the armature, then although the reflected waves still cancel, the force. owing to the incident wave is reduced by the factor $\cos \theta$, We estimate that $\theta$ does not exceed 2 deg; the error is thus less than \pm 0.06 percent, and the total error associated with the target is about \pm 0.4 percent. The above analysis actually applies to a wedge having its edge perpendicular to the plane in which the angular errors are estimated, but it is likely to be adequate for a cone as well. As already remarked, it appears that there is no sensible error owing to reflection of sound back from the wall of the tank. 
An error of another kind has to do with the attenuation of sound in the medium. Although the apex of the target is set very close to the transducer, the rest of the target is affected by sound which has travelled some distance. The most remote part of the conical target is at a distance equal to the radius, $r$, of the active element, so that the intensity, and hence the radiation pressure, at the edge of the beam is reduced by the factor exp $(-2 \alpha r)$; elsewhere the reduction is less. This factor is overestimated because some additional force, owing to streaming (at the modulating frequency) is present, but it is not known, in a particular case, how much. Thus the measured radiation force should be increased by some factor between unity and exp (2or); we may therefore multiply it by $[\exp (2 \alpha r)+1] / 2$ and attach an error of $\pm 100[\exp (2 \alpha r)-1] / 2$ percent. Examples of this error for typical frequencies and values of $r$, are given in Table 1 , which also accumulates the estimated limits of error from all known sources. The value of $\alpha$ for water is taken as $24 \times 10^{-15} \mathrm{sec}^{2} \mathrm{~m}^{-1}$ at $22^{\circ} \mathrm{C}$. [11]. For other temperatures see Pinkerton [11] or the A.I.P. Handbook [12].

It is seen that for frequencies of $5 \mathrm{MHz}$ and less, the principle source of error is the uncertainty in the balancing force $F_{p}$, whereas for higher frequencies it is the uncertainty in the correction for attenuation. 
4. SOME RESULTS

4.1 Linearity and comparison with other methods

The linearity of the apparatus was assessed by measurement, at ten or so power levels, of each of a number of transducers which are themselves expected to be linear. For this purpose we have on hand a collection of very carefully made transducers having air-backed, $x$-cut quartz discs as active elements. They were designed and fabricated by T. L. Zapf and his co-workers in the Electromagnetics Division at NBS Boulder.

For each transducer, measurements of the peak input voltage $E_{1}$, the ratio: $E_{2} / E_{1}$, and the peak radiation force $F_{p}$ were made at about 10 different power levels. In all cases the frequency was that of the lowest resonance. Equation (7) may be rewritten as

$$
\left|P_{P}\right|=G_{r} E_{1, c} c^{2} / 4,
$$

in which the power $\left|P_{P}\right|$ is $c|p|$, from eq. (5) and

$$
E_{1, c^{2}}=E_{1}^{2}\left(1-E_{2}^{2} / E_{1}^{2}\right)
$$


We do not know, in advance, that a plot of $P_{p}$ vs $E_{1, c}$ would go through the origin, because the determination of $\mathrm{E}_{1}$ involves a correction for the break-voltage of the diodes in the slideback voltmeter, and this quantity has no precise definition. Thus we modify Eq. (9) to read

$$
\left|P_{P}\right|=a+G_{r} E_{1, c}{ }^{2} / 4,
$$

and then fit to it, by least squares, the values of $\left|P_{p}\right|$ and $E_{1, c}$ calculated from the measurements. The temperature of the water was read to within $0.1{ }^{\circ} \mathrm{C}$. and the values of $\mathrm{c}$ for use in eq. (5) were taken from Del Grosso and Mader.

The results are given in Table II for 14 different transducers. The smallest power measured was about $1 \mathrm{~mW}$ for the 2-MHz transducer, $2 / 1$, and the largest was about $528 \mathrm{~mW}$ for the $15-\mathrm{MHz}$ transducer, $3 / 1$. These two have also the smallest and largest values of $G_{r}$; the power outputs were chosen so that the input voltages would lie in a convenient range.

In all cases the fit of the data to the assumed Bq. (10) is very good; the residual standard deviation of the fit is less than one percent of the smallest power used except for $3 / 1$. The standard deviation of the radiation conductance $G_{r}$ did not exceed 0.15 percent in any case; the average value was 0.09 percent. The random variation of 0.3 percent in setting the null (Section 3.7) was taken from these figures. 
The intercept, $a$, of eq. (10) (not given in Table II) was in all cases small; less than 1 percent of the lowest power level used in 10 cases, less than 2 percent in 3 cases and 3.1 percent in 1 case. Furthermore the standard deviations of these intercepts were substantial, ranging from 0.29 to 10.2 times the intercept itself, with an average value of 1.43. These results establish the validity of eq. (9) and render it highly probable that the transducers are linear in the sense that the output power is proportional to the square of the input voltage and that the apparatus measures something strictly proportional to the output power. These conclusions apply over the power range 1 to $528 \mathrm{~mW}$ and the frequency range 1 to $15 \mathrm{MHz}$ but we believe them to hold over much broader ranges.

Zapf $[14]$ and his co-workers measured the input conductance, G, on resonance of these same transducers. The efficiencies listed in Table II are the values of $G_{r} / G$, the values of $G_{r}$ being those of Table II. They are seen to be very high, as would be expected for well-made, air-backed quartz transducers, except for the two $15 \mathrm{MHz}$ ones. To these efficiencies we attach the uncertainties, listed in Table II, which were calculated on the supposition that the input conductance, G, is accurate to \pm 1 percent. This is a conservative figure.

Further impedance measurements were made by Zapf [14] from which he calculated the radiation conductances, $G_{r}$, and the erficiencies of 
the transducers on the basis of an assumed equivalent circuit for the representation of the several loss mechanisms. We do not make any direct comparisons with these measurements here because we are not certain, in our own minds, as to just how the impedance measurements are to be interpreted. Nevertheless, the two sets of measurements agree within the estimated limits of uncertainty in 11 of the 14 cases. For the $5 \mathrm{MHz}$ transducer, 2/8, the "error bands" fail to overlap by 1.3 percent, and for the two $15 \mathrm{MHz}$ transducers, $3 / 1$ and $3 / 2$, the corresponding figures are 4.5 and 9.5 percent.

Zapf et aZ[15] have designed and constructed a twin, series flow calorimeter for measurement of the total beam power output of ultrasonic transducers over the range 1 to $15 \mathrm{MHz}$. Although there are still some problems with this instrument, especially the persistence of residual standing waves at the lower frequencies, we have used it, after making some modifications, to measure the radiation conductance, $G_{r}$, of the transducers listed in Table II. In all cases the value of $G_{r}$ measured calorimetrically and that measured in the radiation-pressure apparatus agree within the limits of uncertainty estimated by Zapf et at for the calorimeter, namely \pm 7 percent. In fact, in most cases the agreement is much better. However, the radiationpressure value of $G_{r}$ exceeds the calorimeter value in all cases, so that the discrepancy is partly systematic. 
Most of the measurements with the radiation-pressure apparatus were made near $22^{\circ} \mathrm{C}$ but all values of the radiation conductance, $G_{r^{s}}$ quoted in this section have been corrected to $25^{\circ} \mathrm{C}$ to put them on a uniform basis. To do this it was supposed that $G_{r}$ is inversely proportional to the $\rho c$ of the water; $\rho$, the density, is from a handbook and $c$ from Del Grosso and Mader [13]. The effect of temperature change on the quartz itself is unknown, but probably small.

\subsection{Sample frequency-response graphs}

Figure 6 is the recorded frequency response of the 2-MHz, airbacked quartz transducer listed in Table II. It looks like about what one would expect. From recordings of the first peak made on an expanded frequency scale, the $Q$ estimated from the half-power points is close to the expected value of about 17. However, there are some anomalies. The shortening of the third peak is not entirely accounted for by the increased attenuation; perhaps the internal losses are here more significant. Also, the small responses at the "forbidden" frequencies of about 4 and $8 \mathrm{MHz}$ are not artifacts; at higher gain they are seen to be repeatable in detail. We have no ready explanation for this.

Figure 7 shows the responses, at the same input voltage, of two commercial, 1-MHz, wideband contact transducers. They are nominally identical, although not bought as a matched pair. The graphs have roughly the same general shape, but substantial differences in detail are apparent. For instance, No. 284 has less output than No. 283 on 
the first peak, in the ratio 0.8 , but more on the second peak, in the ratio 1.7 .

Figure 8 shows the responses, at the same input voltage, of two commercial, nominally identical, 5- $\mathrm{MHz}$, wideband immersion transducers. The response of No. 3045 is clean and repeatable. That of No. 3042 is spiky and not repeatable; the number of spikes change with power level and sometimes spontaneously. Evidently this transducer is defective. Careful examination under a binocular microscope shows some peculiarities which indicate possible detachment of the facing.

\section{CONCLUSION}

We have described an apparatus, based on modulated radiation pressure, which measures the total sound power output of an ultrasonic transducer either at any desired frequency or frequencies or continuously over a broad range of frequencies. It is stable and easy to use, and the results are absolute. The sensitivity is very high, and the accuracy, although perhaps modest, is more than adequate for the purposes envisaged.

The measurements reported cover the range $100 \mathrm{kHz}$ to is $\mathrm{MHz}$, more or less, but we have used the equipment up to $68 \mathrm{MHz}$. However, we have no good way to assess the limits of error above about $30 \mathrm{Mllz}$. 


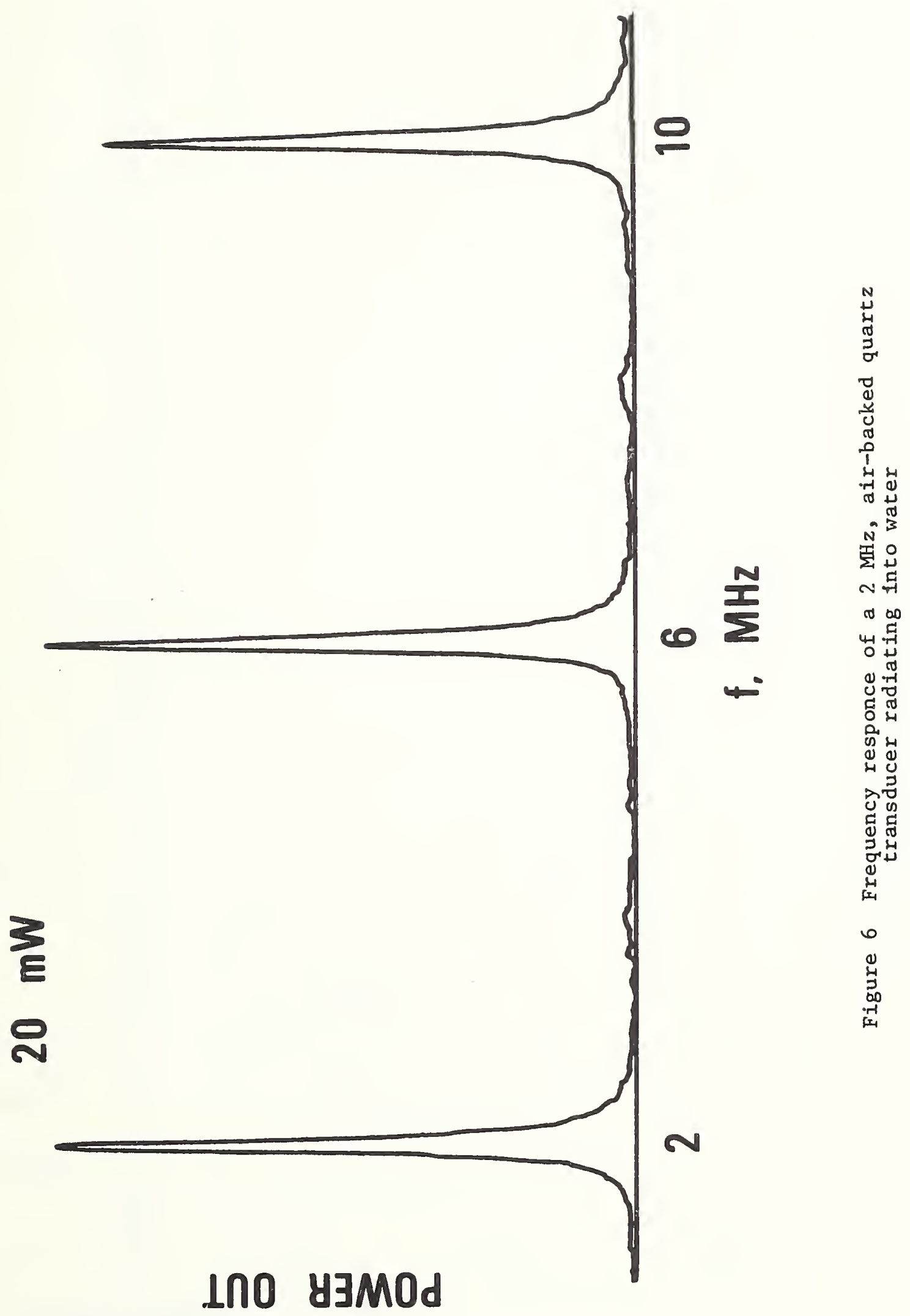




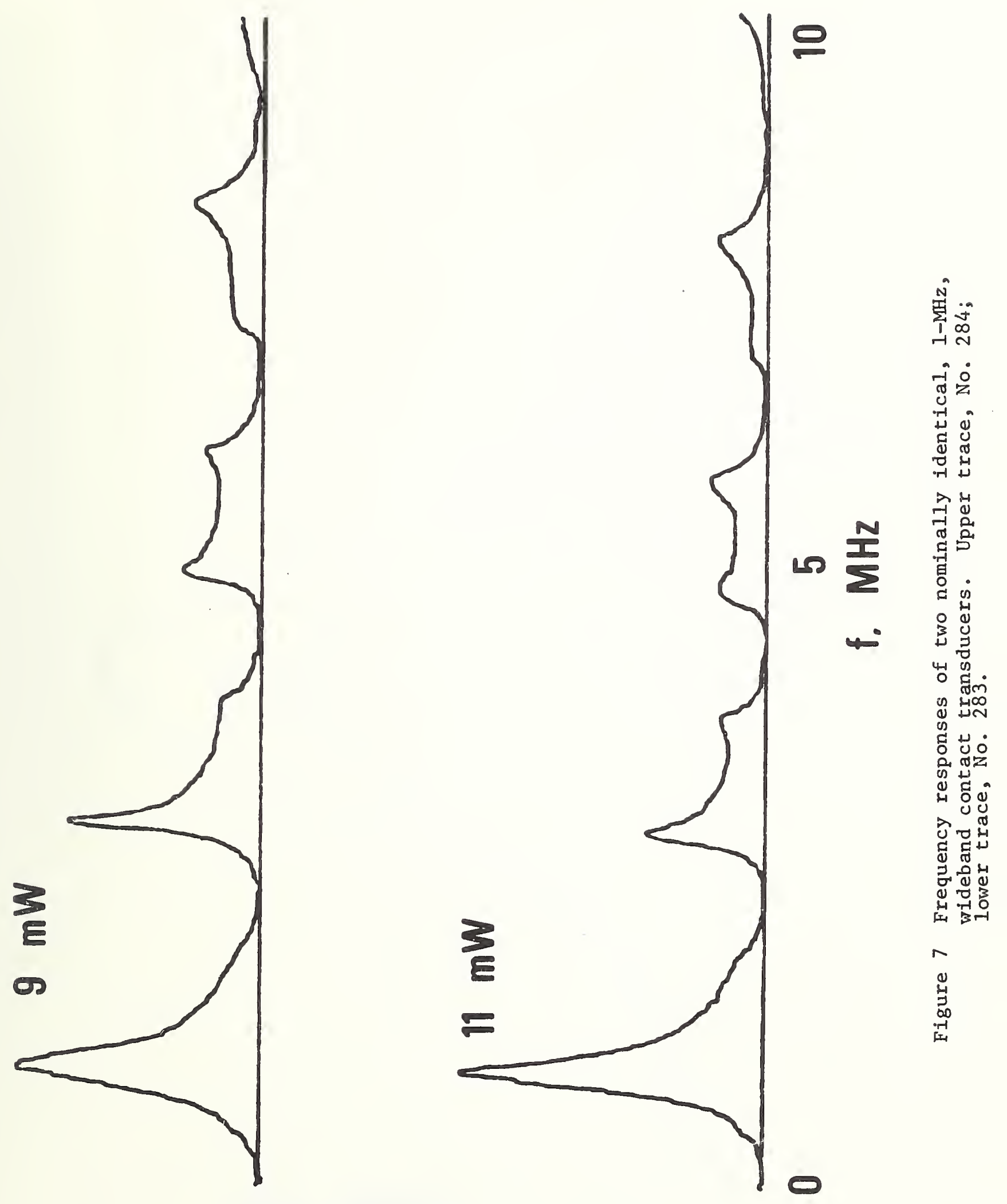

InO yaMOd 



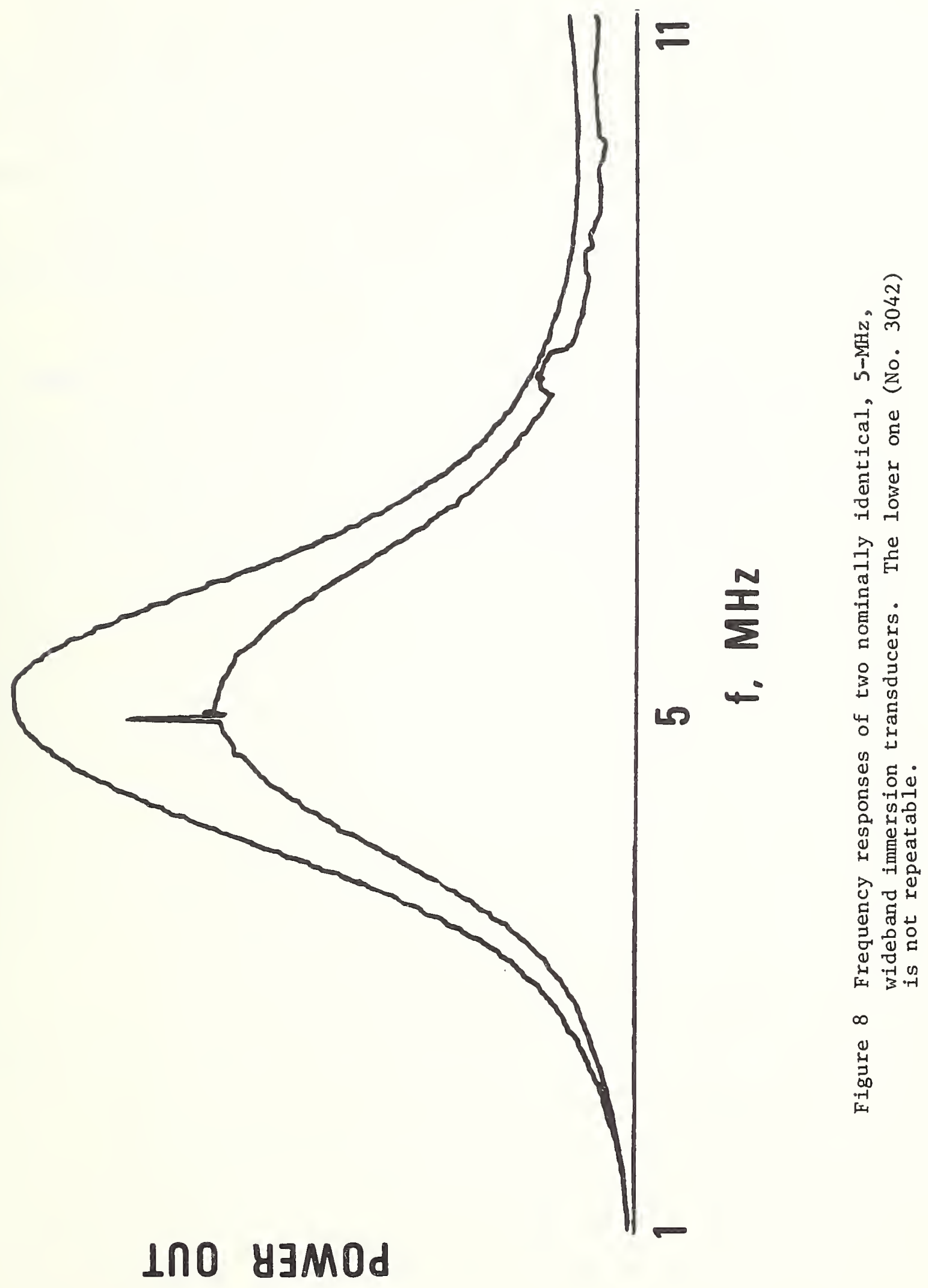



We hope that the apparatus will find use in monitoring the integrity of practical transducers, including those used in non-destructive evaluation and in medicine. We find the method to be especially convenient for measurement of the frequencies of maximum power output and of bandwidth. Also, it has application in medical dosimetry for which, indeed, we have already used it to a limited extent.

Much work remains to be done before it will be practicable to diagnose a defective transducer by examination of the anomalies in its frequency response. It is a matter, mostly, of developing a data base by performing "autopsies" on the transducers. 
6. REFERENCES

[1] J. A. Rooney and W. L. Nyborg, Am J. Phys. 40, 1825-1830 (1972)

[2] J. Zieniuk and R. C. Chivers, U1trasonics 14, 161-172 (1976)

[3] L. J. Sivian, Phil Mag, 7 Series 5, 615-620 (1928)

[4] . A. Barone and M. Nuovo, Ricerca Sci. 21, 516-518 (1951)

[5] F. L. McNamara and R. T. Beyer, J. Acous. Soc. Am. 25, 259-262 (1953)

[6] M. Mokhtar and H. Youssef, J. Acous. Soc. Am. 28, 651-655 (1956)

[7] R. A. Hane1, J. Acous. Soc. Am. 32, 1436-1442 (1960)

[8] F. E. Terman, Radio Engineers' Handbook (McGraw-Hil1, New York, 1943) p. 933, Fig. 41 (c).

[9] F. L. Hermach and E. S. Williams, Comm. and Electr. (July, 1960)

[10] F. E. Borgnis, J. Acous. Soc, Am, 24, 468-469 (1952) 
[11] J. M. M. Pinkerton, Nature $\underline{160}, 128-129$ (1947)

[12] M. Greenspan, Acoustic Properties of Liquids in American Institute of Physics Handbook 3 ed., P. 3-86 ff, D. E. Gray, Ed. (McGraw-Hill, New York, 1972)

[13] V. A. Del Grosso and C. W. Mader, J. Acous. Soc. Am. 52, 14421446 (1972).

[14] T. L. Zapf, Proc. Ultrasonics Symposium, 45-50, IEEE Cat. No. 74 CHO 896-ISIJ (1974)

[15] T. L. Zapf, M. E. Harvey, N. T. Larsen and R. E. Stoltenberg, UZtrasonic Calorimeter for Becon Power Measurements, NBS Technical Nots 686, S D Catalog No. C13.46:686 (U.S. Government Printing Office Wasiningion, D.C. 20402, 1976) 
A. LEVELING CONTROL.

It is desired to hold the voltage on the transducer constant during the frequency sweep. The voltage is leveled at the source output, but this does not prevent the voltage from varying with frequency at the transducer, which presents a varying impedance to a long cable.

The leveling (AVC) circuit is shown in Fig. A-1. The operational amplifier is required to furnish the level-control input of the signal generator with a voltage similar to the upper envelope of the input to the transducer. The envelope desired at the transducer input is synthesized from a negative dc voltage and a sine wave (from the modulation oscillator) both impressed on the summing (-) terminal of the operational amplifier. On this terminal is also impressed the envelope of the actual signal at the transducer input, obtained from a full-wave diode rectifier. Since the suming point is a virtual ground, the feedback holds it at a very small negative potential; therefore the detected modulation envelope is the negative of the synthesized envelope. The protective Zener diode across the voltage-control input of the signal generator limits the maximum excursion to $7.5 \mathrm{v}$.

The diode detector is housed in a small circuit box. Where possible, the input connector is attached directly to that of the transducer, 


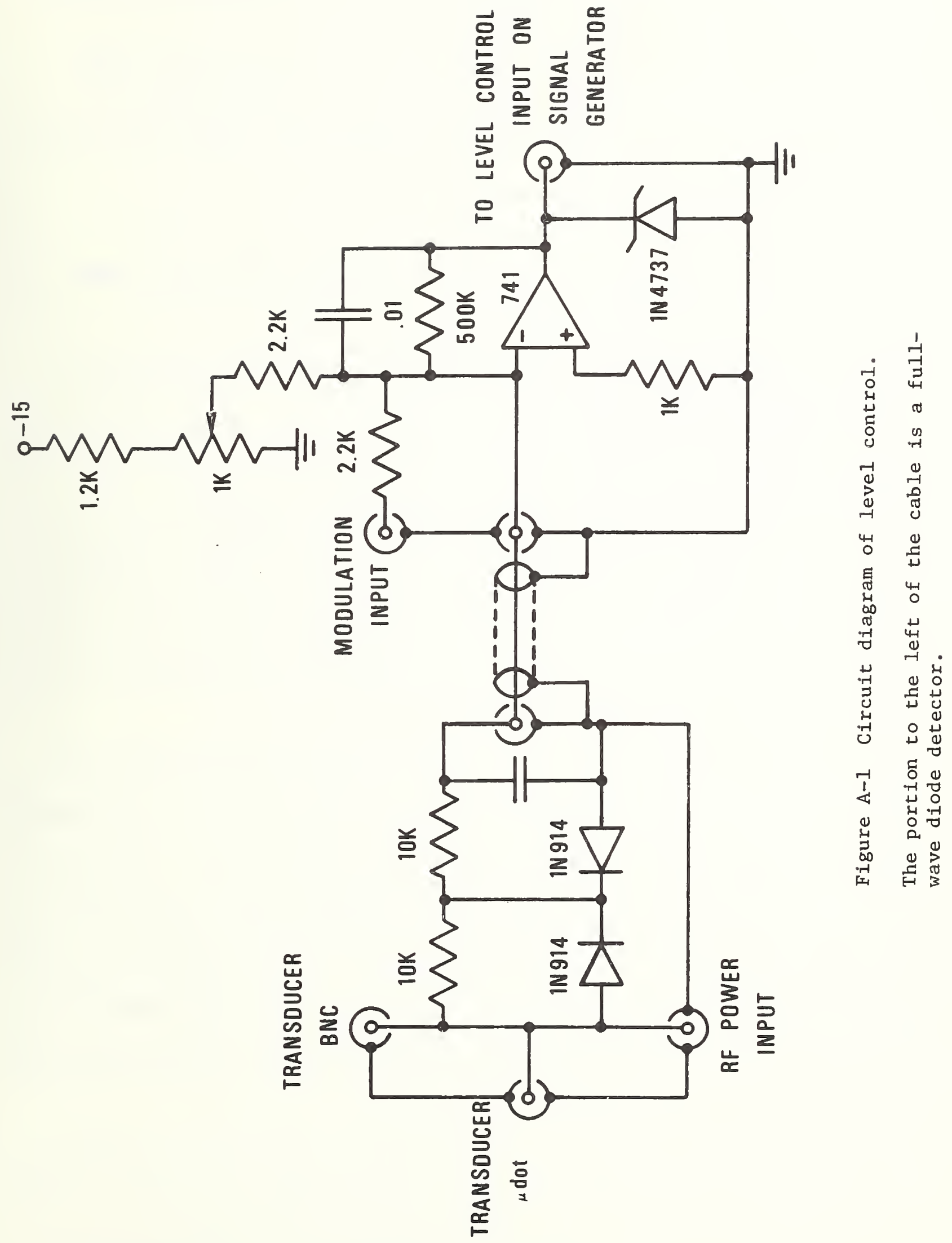



otherwise an adaptor or the shortest possible cable is interposed.

The circuit shown works very well but others, as good or perhaps better, may suggest themselves to the designer.

\section{B. DIODE SLIDEBACK VOLTMETER}

The evolution of the diode slideback voltmeter is shown in Fig. B-1. A primitive circuit, similar to that in Terman [8] is shown at (a). The bias, $E_{d c}$, is set so high that no current flows. It is then reduced to the value at which the least detectable current is observed on the microammeter. Then, if the diode characteristic has a sharp break at 0 volts, the dc bias, as read on the voltmeter, is very nearly equal to the positive peak of the voltage, $E_{a c}$.

Our purpose is the measurement of the peak of a bigh-frequency wave modulated at a low frequency. In this case the effective duty cycle, at the point at which current just begins to flow, is very low, so that the sensitivity of the setting is poor. To remedy this the arrangement show at (b) may be used. The instantaneous current flow, as measured by the voltage drop across the resistor, $R$, is observed on an oscilloscope, which must be provided with a differential input. 
The main problem now is that the rf leakage through the capacitance of the diode makes it necessary to use a low-gain setting on the oscilloscope, so that the sensitivity is still not adequate. A bridge-type circuit, shown in (c), in which the diode capacitance is mostly "neutralized" by the variable capacitance, C, allows the use of a high-gain setting on the oscilloscope, and the conduction point is easily determined to 0.01 volt. Two diodes in series are used to extend the range; the combined capacitance is about $0.1 \mathrm{pF}$. Thus C needs to be very small. In our case $\mathrm{C}$ is the capacitance between two stiff wires in proximity, and is varied by bending a wire. We have not found a germanium diode with a "break point" sharp enough to serve as an unambiguous reference. The break point of the planar silicon switching diode (and no doubt of some other silicon diodes as well) we use (1N4454) is very distinct. It occurs at about $0.46 \mathrm{~V}$ at room temperature, and twice this value (for two diodes) must be added to the indicated reading.

We recapitulate the method of operation.

1. Set the dc bias; $E_{\mathrm{dc}}$, to zero and raise $E_{\mathrm{ac}}$ until the crests of the waveform are just visible on the oscilloscope screen. Measure the peak value of $\mathbf{E}_{a c}$ (an oscilloscope gives adequate accuracy) and call this $\mathrm{E}_{\mathrm{o}^{\circ}}$

2. Set the bias to a value higher than the peak to be measured, apply the unknown voltage, and reduce the bias to the point at which conduction occurs, using the same criterion as in step 1. 

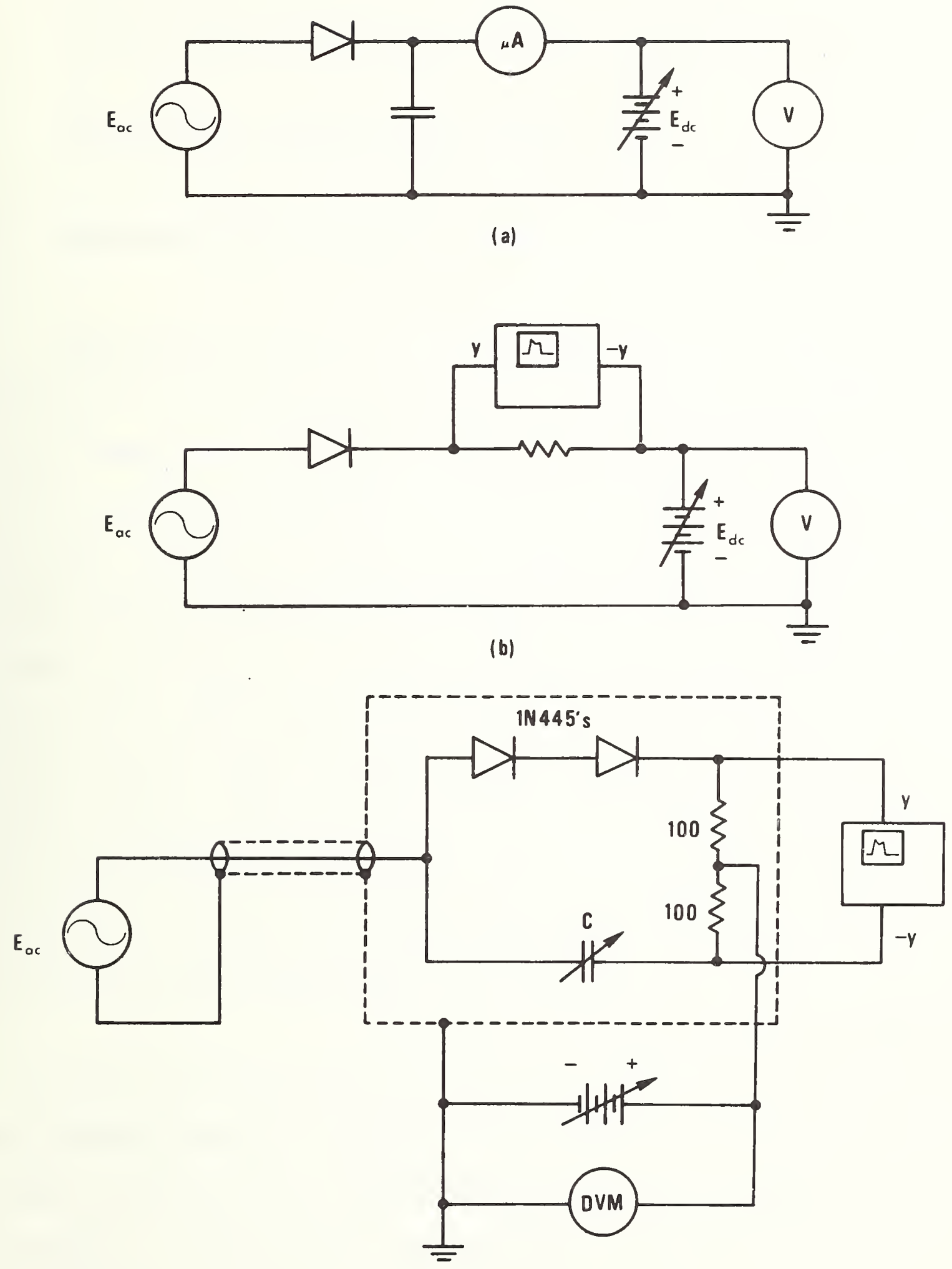

(c)

Figure B-1 Evolution of the diode slideback voltmeter. See text. 

3. Measure the bias using a digital voltmeter and add $E_{0}$; the result is the positive peak of the unknown voltage, $\mathrm{E}_{\mathrm{ac}}$.

Step 1 need be repeated only occasionally.

C. MEASUREMENT AND MONITORING OF BL-PRODUCT

The apparatus is prepared for measurement of the BL-product by replacement of the target by a weight pan, insulated from the armature. The pan is loaded with (analytical) weights and the deflection, which amounts to about $2.5 \mu \mathrm{m}$ per gram-weight, is restored to zero by a current through the coil. The zero, or reference position is indicated by a simple circuit which detects changes in capacitance between the weight pan and a plate mounted on the frame. The gap between these is about $1 \mu \mathrm{m}$ at the reference position, the capacitance about $280 \mathrm{pF}$. A roughly constant current is provided by a $1-\mathrm{MHz}$ oscillator in series with $27 \mathrm{pF}$, so the voltage across the gap is nominally proportional to the gap itself. This voltage is measured with a simple diode voltmeter (a Ge diode and a laboratory multimeter); the sensitivity amounts to about $0.1 \mu \mathrm{m}$, corresponding to an increment of 0.04 gram-weight (out of 10 or $20 \mathrm{~g}$ ).

The scheme for monitoring of the BL-product is based on the fact that the total charge, $q$, delivered by the moving coil to a short circuit, owing to the addition to or removal from the weight pan of a weight, $W$, is independent of the time history of the loading. To see this, note that the instantaneous voltage, $e_{c}$ across the moving coil is

$$
e_{c}=R i-B I v \text {, }
$$


in which $i$ is the current and $v$ the velocity, both instantaneous. The impedance, $R$, of the coil has been made to be very nearly resistive by swamping the slightly reactive part with a series resistor. The (extended) coil is connected to the input of an integrating amplifier, i.e. an operational amplifier having capacitive feedback and practically zero input impedance. Under, the these conditions, $e_{c}=0$, and the charge, $q$, is

$$
q=\int_{0}^{\infty} i d t=\frac{B L}{R} \int_{0}^{\infty} v d t,=\frac{B L}{R} x,
$$

in which $\mathrm{x}$ is the total displacement produced by the weight, W. Noting that $x=w / k$, in which $k$ is the stiffness of the moving system, and that the output of the operational amplifier is $e_{0}=q / c$, in which $c$ is the feedback capacitance, we get

$$
e_{0}=\frac{B L}{R C K} W
$$

This if $R, C$ and $k$ are constant, $e_{0} / W$ is a measure of the BL-product and can be used to monitor it. The measuring circuit is shown schematically in Fig. C-1. Rather high-grade components are required. A chopperstabilized operational amplifier, with provision for cancellation of drift is mandatory. For the swamping resistor, which is part of $R$, and is also the input resistor of the operational amplifier, we use a 20-ohm, "noninductive" wire-wound, precision resistor and for the feedback capacitor, C, a $1 \mu \mathrm{F}$ polycarbonate capacitor, chosen for large time constant and low dielectric absorption. 


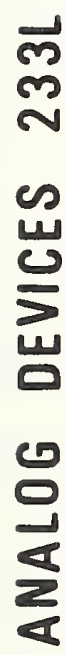
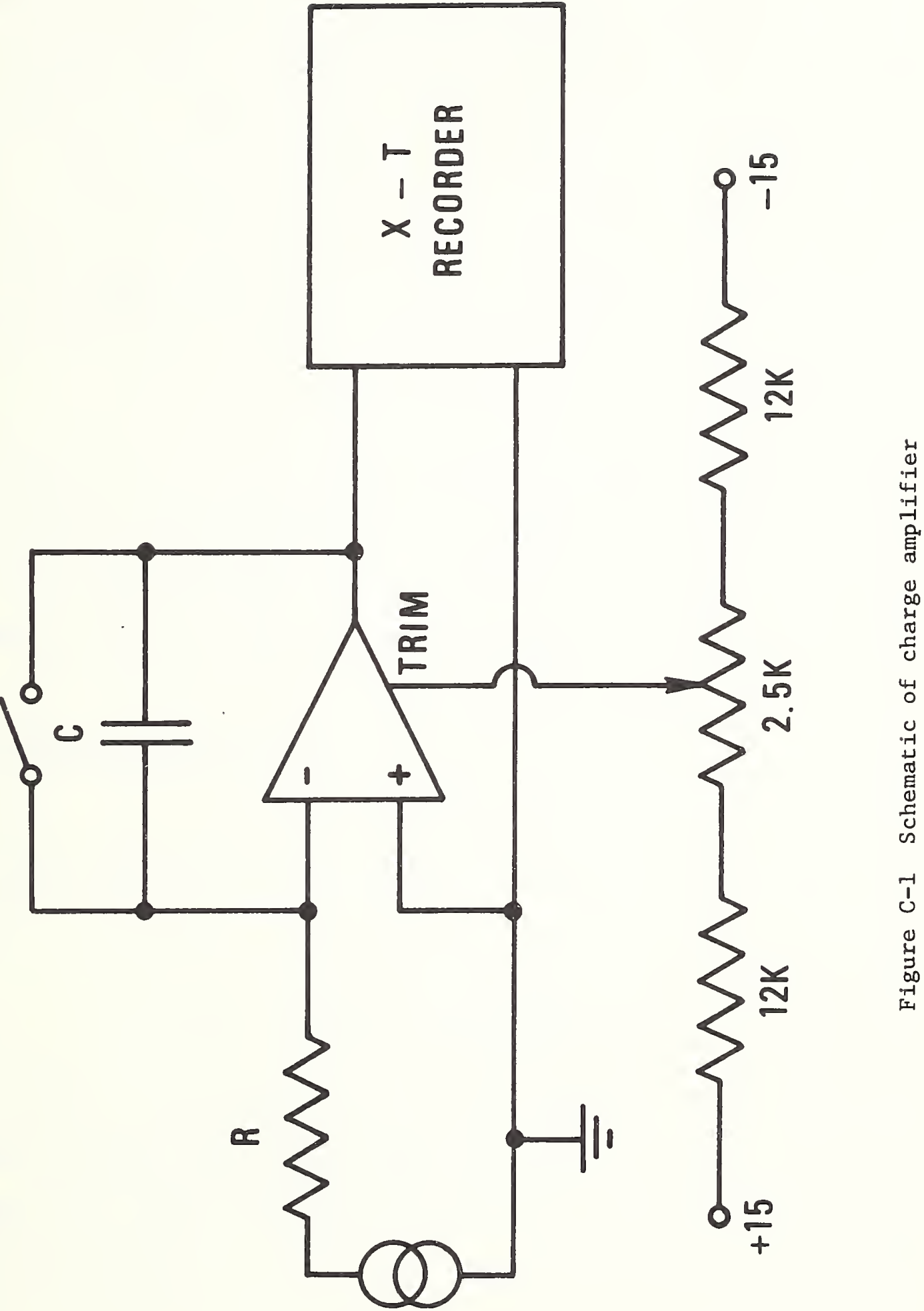

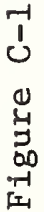

4
$\theta$ 

Our procedure is as follows: The output of the integrator is observed on a $y, t$-recorder while the drift control is set to yield the smallest possible drift. A weight, usually $20 \mathrm{~g}$, is placed on the weightpan and removed after the output has settled to a constant value except for drift. This operation is repeated a number of times and the voltage change, owing to the additions and abstractions of the weight, are averaged. Settling occurs in a few tenths of a second, so it is not necessary to correct for drift in most cases.

In a typical set of 12 such measurements the standard deviation is about one percent of the average. Thus the method seems suitable for the detection of large changes in the BL-product, such as might be caused by mechanical shock or a large demagnetizing field.

D. PHASE SHIFTER AND ATTENUATOR

The phase shifter is shown schematically in Fig. D-1. The output voltage is

$$
e_{0}=e_{+}-\left(e_{i}-e_{t}\right)=\frac{-1+j \omega R C}{1+j \omega R C} e_{i} \text {. }
$$

Thus the magnitude of the gain is unity, and the phase is $\tan ^{-1}(-\omega R C)$ in the second quadrant minus $\tan ^{-1}$ wRC in the first (If $R$ and $c$ are interchanged, the result is the same except that $\tan ^{-1}(-\omega R C)$ is the angle in the fourth quadrant.) 
In our case the operational amplifier is a type $741, r=10 \mathrm{k}, \mathrm{C}=1, \mathrm{~F}$, and $R$ is a 20-k potentiometer in series with $3.3 \mathrm{k}$. The output drives a $1-k$ potentiometer which provides the fine amplitude control at the input of the attenuator.

A similar phase-shifter, but with $R$ fixed at $10 \mathrm{k}$, drives the "modulation-input" jack of Fig. A-1. It serves to provide a suitable operating point for the variable phase shifter. Both phase shifters are driven by the modulation oscillator through a gain stage consisting of a type 741 operational amplifier provided with a 10-k input resistor and a 100-k potentiometer as the feedback resistor. 


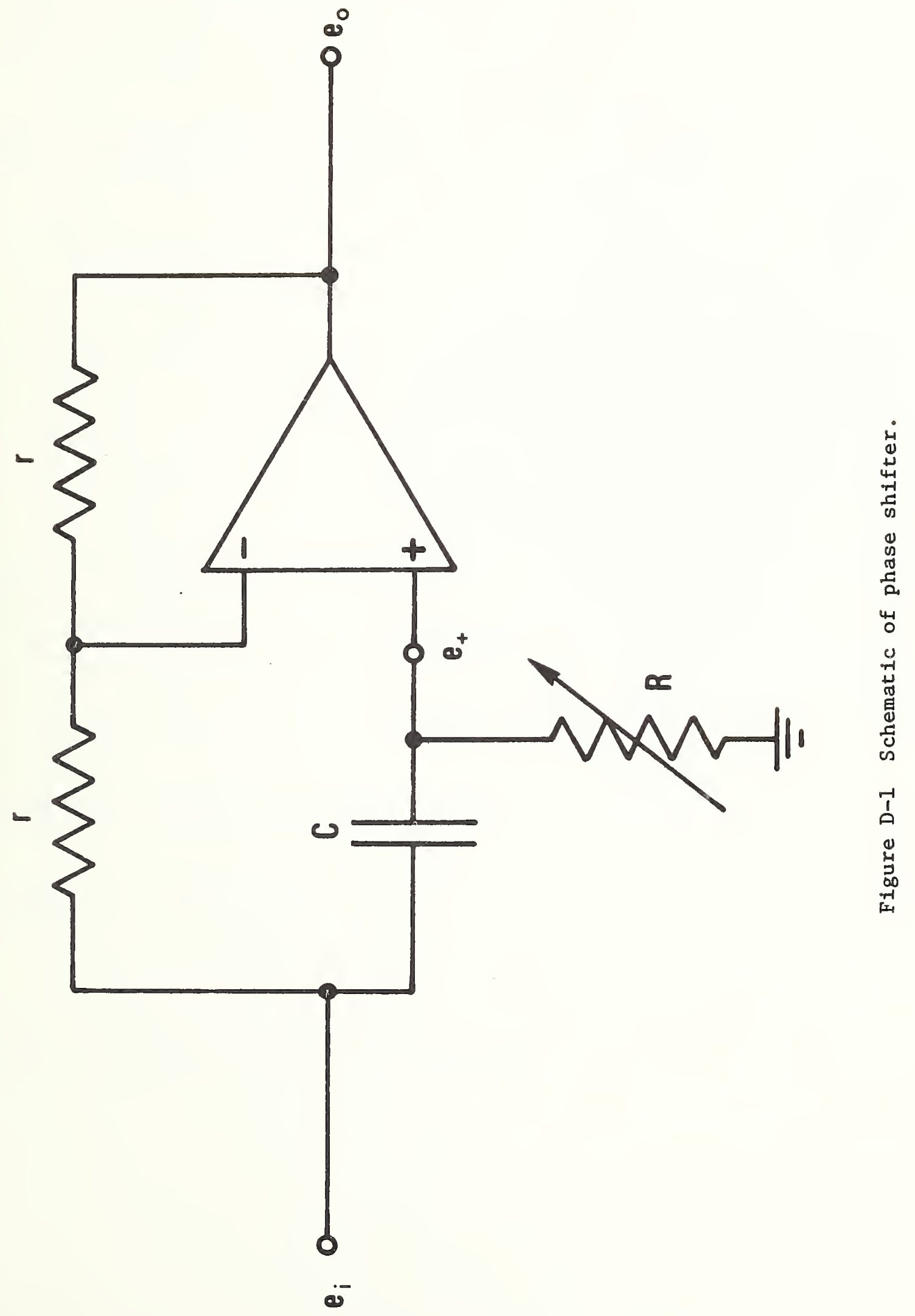


TABLE I. Estimated Limits of Uncertainty ${ }^{(a)}$

Uncertainty owing to

\begin{tabular}{|c|c|c|c|c|}
\hline Frequency & Radius, $r(b)$ & Voltage, $\mathrm{E}_{1}$ & Attenuation & Tota1 (c) \\
\hline $\mathrm{MHz}$ & $\mathrm{cm}$. & \pm percent & \pm percent & \pm percent \\
\hline 1 & 2.0 & 0.40 & 0.05 & 2.2 \\
\hline$\underline{2}$ & 1.5 & 0.40 & 0.14 & 2.3 \\
\hline 3 & 1.2 & 0.40 & 0.26 & 2.4 \\
\hline 5 & 1.0 & 0.40 & 0.60 & 2.8 \\
\hline 10 & 0.8 & 0.40 & 1.96 & 4.1 \\
\hline 15 & 0.6 & 0.40 & 3.35 & 5.5 \\
\hline 20 & 0.5 & 0.80 & 5.04 & 7.6 \\
\hline $25^{-}$ & 0.5 & 0.80 & 8.09 & 10.7 \\
\hline 30 & 0.4 & 0.80 & 9.43 & 12.0 \\
\hline
\end{tabular}

(a) The errors are, for the most part, systematic.

(b) Typical value; affects attenuation estimate only.

(c) Includes frequency-independent errors as follows: ratio $E_{2} / E_{1}, \pm 0.07$ percent; balancing force, $\mathrm{F}_{\mathrm{p}}, 1.3 \%$; target related, 0.41 percent. 


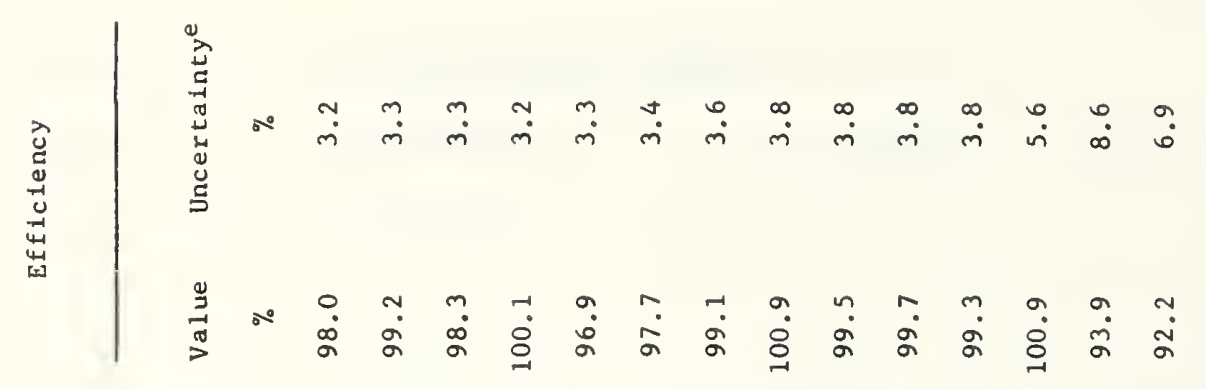

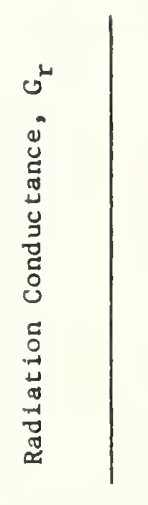

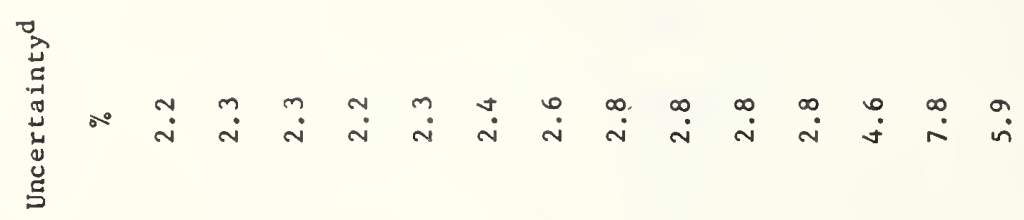

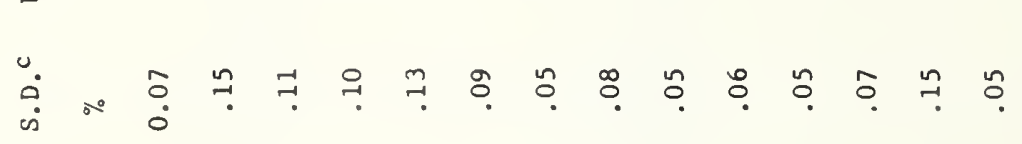

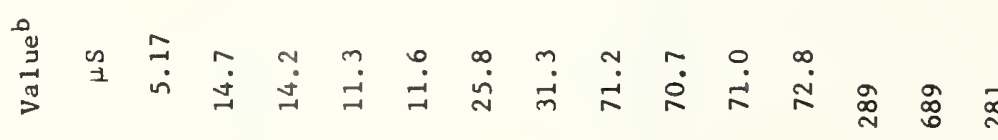

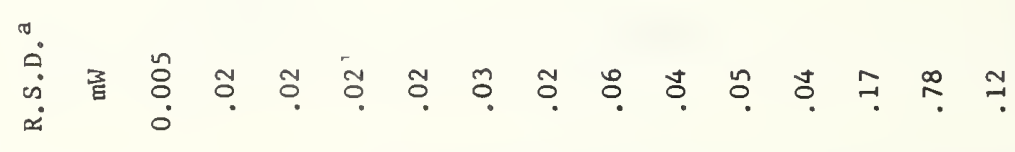

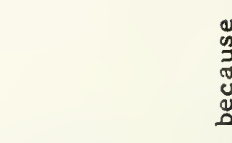

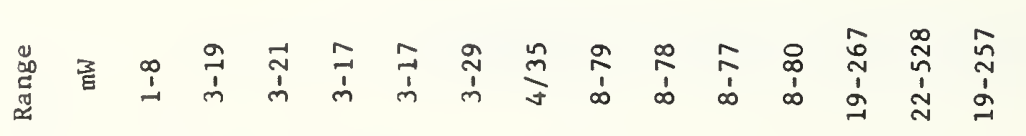

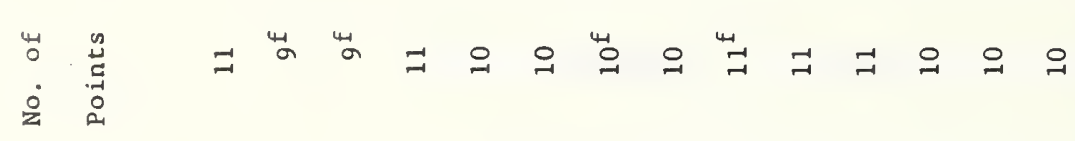

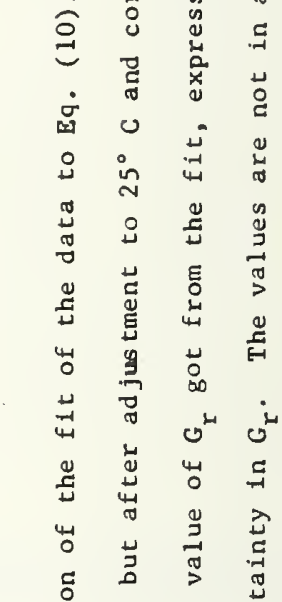

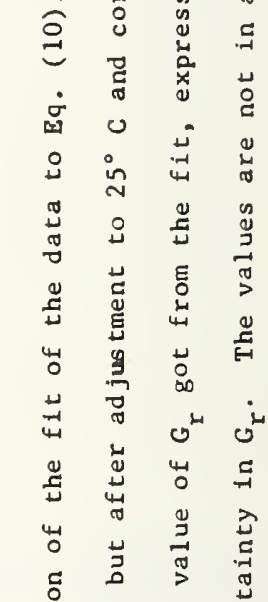

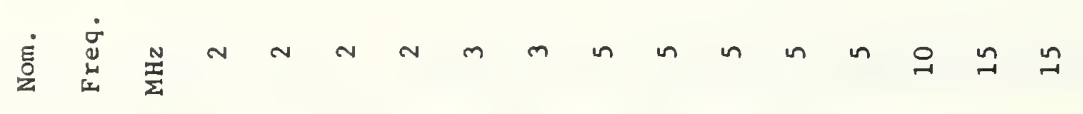

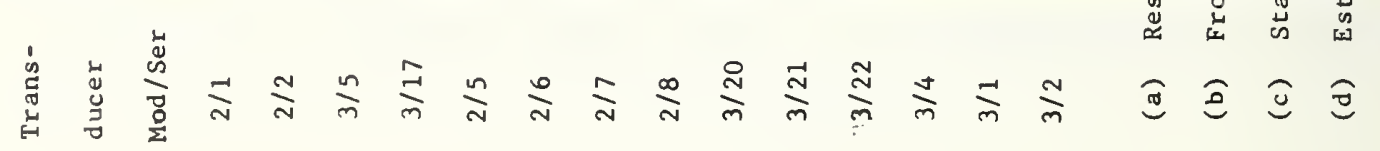


NBS.114A (REV. 7.73)

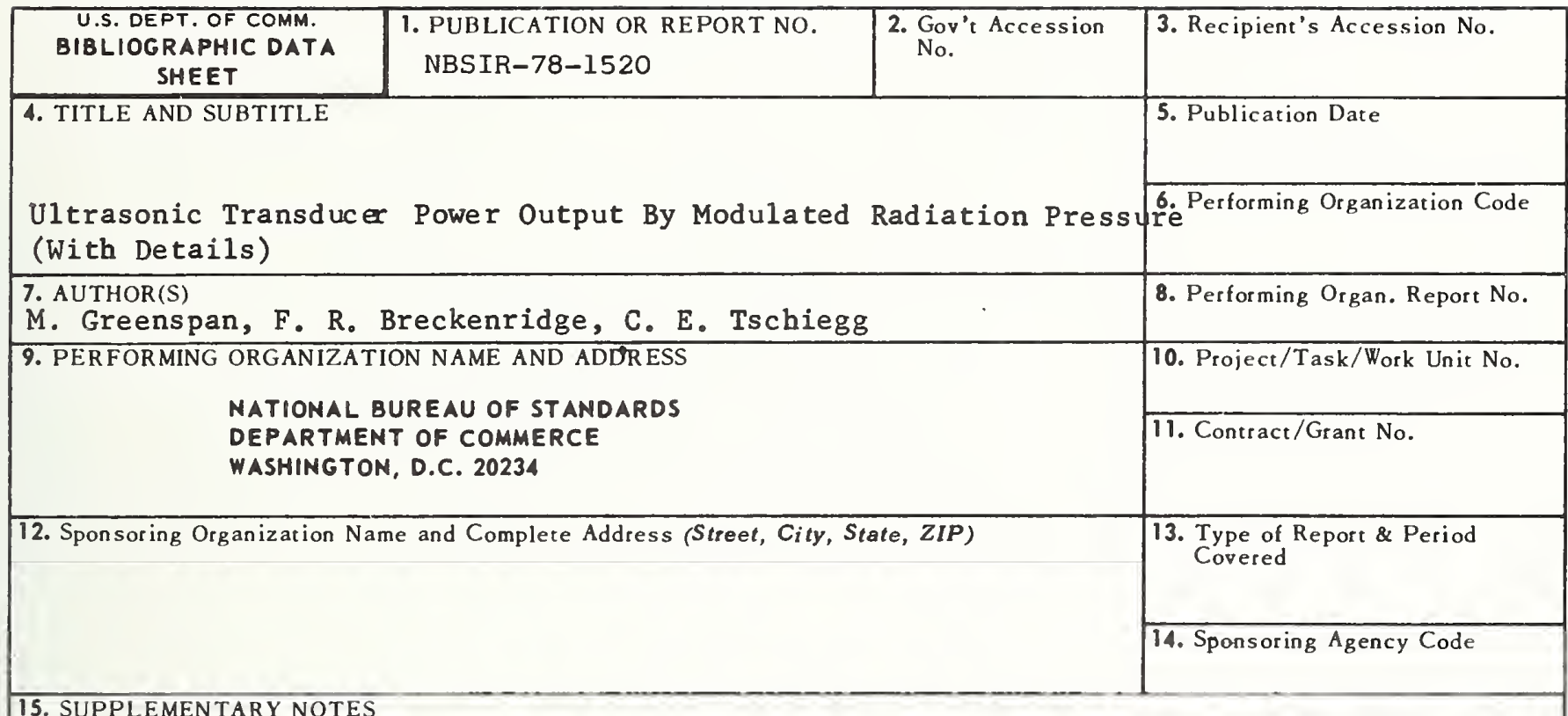

\section{SUPPLEMENTARY NOTES}

16. ABSTRACT (A 200-word or less factual summary of most significant information. If document includes a significant bitliography or literature survey, mention it here.)

We have set up and are using an apparatus for the measurement of total sound power output of a piezoelectric transducer radiating into water. This apparatus combines the better features of previously used methods which depend on radiation pressure. The input is modulated at a low frequency and the output power is intercepted by a target which experiences a force at the modulation frequency. The target is mounted on the armature of an electromagnetic receiver provided with an independent coil through which a current at the modulation frequency is adjusted in amplitude and phase, either manually or automatically by feedback, to arrest the motion of the armature. When the armature is stationary the force depends only on the current, and the apparatus can be calibrated using direct current and dead weights. It is thus absolute. In practice, the carrier frequency is swept over any part of the range 0.1 to $15 \mathrm{MHz}$ while a recording of power output versus frequency is made. The results of comparisons made with those of other methods are encouraging. Examples of curves from normal and defective transducers are shown.

17. KEY WORDS (six to twelve entries; alphabetical order; capitalize only the first letter of the first key word unless a proper name; separated by semicolons) calibration of transducers; medical ultrasonics; modulated radiation pressure; radiation pressure; transducers; non-destructive evaluation; ultrasonic transducers.

18. AVAILABILITY Unlimited

For Official Distribution. Do Not Release to NTIS

Order From Sup. of Doc., U.S. Government Printing Office

Washington, D.C. 20402, SD Cat. No. C13

Order From National Technical Information Service (NTIS) Springfield, Virginia 22151

\begin{tabular}{|l|c|}
\hline $\begin{array}{l}\text { 19. SECURITY CLASS } \\
\text { (THIS REPURT) }\end{array}$ & 21. NO. OF PAGES \\
UNCL ASSIFIED & 50 \\
\hline $\begin{array}{l}\text { 20. SECURITY CLASS } \\
\text { (THIS PAGE) } \\
\text { UNCLASSIFIED }\end{array}$ & 22. Price \\
\hline 44.50
\end{tabular}



$\downarrow$

I

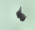

$\checkmark$ 
